ISSN 1516-635X Oct - Dec 2015 / v.17 / n.4 / 405-418

http://dx.doi.org/10.1590/1516-635x1704405-418

\section{A Review of Approaches Targeting the Replacement of Coccidiostat Application in Poultry Production}

Review

\section{-Author(s)}

\section{Barbour EK \\ Ayyash DB" \\ lyer A"II \\ Harakeh SIV \\ Kumosani T"}

Department of Animal and Veterinary Sciences, Faculty of Agricultural and Food Sciences, American University of Beirut; adjunct to Biochemistry Department, King Abdulaziz University, Jeddah, Saudi Arabia.

" Department of Animal and Veterinary Sciences, Faculty of Agricultural and Food Sciences, American University of Beirut.

III Biochemistry Department, Faculty of Science and Experimental Biochemistry Unit, King Fahd Medical Research Center, King Abdulaziz University, Jeddah, Saudi Arabia.

Iv Special Infectious Agents Unit - Biosafety Level 3, King Fahd Medical Research Center, King Abdulaziz University, Jeddah, Saudi Arabia.

\section{ABSTRACT}

The classical and the most commonly used approach for the prevention of coccidiosis in chickens is the incorporation of synthetic coccidiostats into their feed during the first weeks of their life. This approach has been challenged by consumers, objecting against residual antimicrobials and drug resistant microorganisms that may contaminate poultry products. Moreover, the coccidiostat application approach has been challenged in the last decade by the emerging regulations in the developed world, targeting the cessation of such a practice. The pressures from the consumers as well as from regulation agencies resulted in a great need for alternative methods to reduce, or completely replace the use of coccidiostats in modern chicken production. This replacement requires seeking for safer products that do not have any negative impact on the consumer's health. Such products are very much in demand, especially in organic poultry farming. The purpose of this review is to present approaches for the replacement of coccidiostat application in chickens through improvements in poultry house management, research in vaccine developments, and application of holistic natural products for the prevention of the economic losses resulting from coccidiosis.

\section{INTRODUCTION}

Coccidiosis is a major parasitic disease affecting the poultry industry worldwide. It is initiated by the exposure of chicken to a sufficient dose of coccidia that can produce clinical signs and intestinal injuries. Eimeria is a genus of Apicomplexan parasites that includes various species responsible for the development of coccidiosis. All species of Eimeria invade the lining of the intestine; however, seven species are considered of economic importance, due to their proven pathogenicity namely, Eimeria acervulina, E. brunetti, E. maxima, E. mitis, E. necatrix, E. praecox, and E. tenella. The significant role that Eimeria hagani and E. mivati have in coccidiosis is still not well-established (Tsuji et al., 1997; Vrba et al., 2011).

The simultaneous field infection with two or more species of Eimeria is common, in which each species causes an independent and recognizable intestinal injury, apart from the other species. Coccidia are transmitted to the host through oral fecal ingestion. The development of the parasite Eimeria includes both an exogenous phase, where oocysts sporulation takes place in the environment to become infective, and an endogenous phase, where asexual and sexual stages of development occur, thus leading to the lysis of the host intestinal tissue (Conway \& Mckenzie, 2007)

The common outbreaks by coccidiosis in chicken required a preventive interception through the past decades by the application 
of coccidiostats in their feed. A continuous in-feed low concentration of anticoccidial drugs to control Eimeria was reported early in the 1930 s and mid-20 ${ }^{\text {th }}$ century (Grumbles et al., 1948; Levine, 1939). These researchers showed for the first time that it was possible to control coccidiosis by the continuous inclusion of a low level of a drug in the feed of chickens (prophylaxis or prevention). However, the use of suboptimal levels of the anticoccidial drugs may increase the probability of selecting drug-resistant strains (Chapman, 1984). Shortly after introduction of sulphaquinoxaline and nitrofurazone, resistance had been reported (Cuckler \& Malanga, 1955; Waletzky et al., 1954). Since that time, many reports concerning anticoccidial drugs resistance were reported (Chapman, 1997). It is therefore possible that in medicated birds adequate parasite multiplication may occur, promoting the development of immunity, which allowed producers to increase the duration of the withdrawal period (less cost or less food residues), at the risk, however, of increased susceptibility to coccidiosis and outbreaks (McDougald \& Reid, 1971). From a practical point of view, it is important not to withdraw anticoccidial drugs ahead of time, since birds may not have developed solid immunity. Solid immunity in medicated birds did not develop until birds were 6 to 7 weeks of age (Chapman, 1999a,b).

\section{POULTRY HOUSE MANAGEMENT IN CONTROL OF COCCIDIOSIS}

Eimeria has a high reproductive ability, thus practically it would be very difficult to keep the environment around the chickens free from these organisms. The global control of chicken coccidial infections in the poultry industry is becoming harder due to the high stocking density of the flocks. Moreover, the present global climate warming enhances coccidial multiplication. Furthermore, the resistant nature of the coccidial oocyst's wall helps protecting the oocyst from desiccation and from the harsh effects of chemical disinfectants, thus ensuring its long term survival in the farm environment. This survival helps in its consequent dissemination across the different poultry houses, via many vectors including mainly employees, equipment, rodents, and/or insects. Documented research indicated that the enhanced risks of coccidiosis are environmental and management factors, as well as hygienic practices that are exercised on the farm, including visitors, presence of feeders and drinking systems that are difficult to clean, and the high probability of carryover of this parasite from previous infected flocks (Graat et al. 1998; Belli et al. 2006).
Reports showed that coccidial oocysts can be easily inactivated by bacteria and ammonia present in the litter after remaining in the fecal droppings for a period of three weeks (Williams, 1995). Many poultry producers opted to remove the used litter, expose the farm house to fresh air for a period of 2-3 weeks, and then add the new fresh bedding before introducing the new flock. Other producers have relied on a thorough cleaning and disinfection of the poultry house and used equipment before the introduction of a new flock. The latter is a husbandry practice that is has been increasingly adopted, due to the decreasing efficacy of anti-coccidial drugs and the increasing use of live vaccines (Allen \& Fetterer, 2002). These hygienic practices led to the emphasis of biosecurity measures to prevent the introduction of new Eimeria spp. to the poultry house, and to sustain the reduction of the number of infective endemic oocysts carried by previous flocks. The degree of sporulation and infectivity of the oocyst count found in the litter determines the level of challenge to the chickens, and predicts the course of the disease progression in the flock, influencing significantly the epidemiology of coccidiosis.

The degree of sporulation is determined by environmental factors like temperature, humidity and aeration. Ambient temperature of $25^{\circ} \mathrm{C}$ and relative humidity greater than $60 \%$ will favor the oocyst sporulation and viability (Razmi \& Kalideri, 2000). The percentage of chicken coccidial sporulation is higher in dry litter than in wet litter, which is most likely due to the buildup of bacteria, ammonia and the poor aeration in wet litter, resulting in loss of oocyst viability (Waldenstedt et al., 2001). However, increasing litter humidity is not recommended in broiler production as it causes skin burns, footpad lesions and consequent lameness. In addition, proper ventilation is recommended for better performance of the bird, but it provides a drier litter that favors sporulation. Reducing bird density seems to be the proper management practice for reducing oocyst accumulation in the litter, and lowering the chances of occurrence of an outbreak of clinical coccidiosis (Chapman et al., 2002).

\section{VACCINES IN CONTROL OF COCCIDIOSIS}

The development of vaccines for protecting broilers against coccidiosis targeted mainly the replacement of the practice of incorporating coccidiostats in the feed. Protective immunity against coccidiosis in chicken can be in the form of an active or passive immunity response, which confers resistance in case of an exposure to 


\section{A Review of Approaches Targeting the Replacement of Coccidiostat Application in Poultry Production}

Eimeria in the field. The degree of resistance and reduction of pathogenic effects are evaluated by the presence of milder gross lesions, lower oocyst output, and increased performance of the birds.

The developed vaccines for coccidiosis were mostly live, divided into two categories namely, nonattenuated and attenuated vaccines. Other minor trends in the development of coccidial vaccines include subunit, recombinant, and DNA-based vaccines.

It is of paramount importance to withdraw the anticoccidial drug from the chicken feed when the administered live vaccine contains live strains that are susceptible to that drug. It is worth noting that live vaccines usually contain strains that are sensitive to commonly used anticoccidial drugs (Peek \& Landman, 2006). Live vaccines can modulate the field strains of Eimeria by respective reduction of their resistance to anticoccidial drugs, and by lowering of their virulence through exchange of genetic information between drug-sensitive attenuated strains in the vaccine and the wild-type strains in the local population of the farm (Williams, 1998). The use of live vaccines for broiler chickens was restrictive for a period of 50 years. Their primary use was for layers and breeders (Shirley et al., 1995). The use of live vaccines in broiler flocks increased significantly during the last decade, mainly due to the improvement of management practices around the globe (Williams, 2002). Live vaccines contain strains that are either attenuated (precocious strains) or nonattenuated (virulent, wild-type strains). An overview of these available commercial registered live vaccines is compiled by William (2002) and Peek \& Landman (2011) (Table 1). Live commercial vaccines are divided into non-attenuated and attenuated categories.

\section{Non-attenuated vaccines}

The mostly known commercialized non-attenuated vaccines used for protection against coccidiosis in chicken are the following:

Coccivac $^{\circledR}$ (Schering-Plough Animal Health, USA): The first registration of this live non-attenuated vaccine was in 1952. This vaccine contains a mixture of live, wild-type strains of Eimeria species that are sensitive to anticoccidial drugs. Vaccination is performed via ocular, hatchery spray, water or feed spray, at an age of 1-14 days, and in a single dose. The Coccivac has two kinds, one that is tailored for protection of layers and breeders (Coccivac $\left.{ }^{\circledR}-\mathrm{D}\right)$, and the other type is for protection of broilers against coccidiosis (Coccivac ${ }^{\circledR}-B$ ). The Coccivac ${ }^{\circledR}$-D contains a mixture of eight species of Eimeria, namely E. acervulina, E. brunetti, E. hagani, E. maxima, E. mivati, E. necatrix, E. praecox, and E. tenella, while the $\operatorname{Coccivac}^{\circledR}-B$ contains only four species namely, E. acervulina, E. maxima, E. mivati, and E. tenella.

Table 1 - Some attenuated and non-attenuated commercial vaccines (Peek \& Landman, 2011)

\begin{tabular}{|c|c|c|}
\hline & Eimeria species & Attenuation \\
\hline Advent $\circledast$ (Novus International) & E. acervulina, E. maxima, E. tenella & Non-attenuated \\
\hline CocciVac®-B (Schering Plough Animal Health) & E. acervulina, E. maxima, E. mivati, E. tenella & Non-attenuated \\
\hline CocciVac®-D (Schering Plough Animal Health) & $\begin{array}{l}\text { E. acervulina, E. maxima, E. brunetti, E. mivati, E. } \\
\text { tenella, E. necatrix, E. praecox, E. hagani }\end{array}$ & Non-attenuated \\
\hline CoxAbic® (Abic biological Laboratories) & E. acervulina, E. maxima, E. tenella & Killed antigen of E. maxima gametocytes \\
\hline $\begin{array}{l}\text { Eimerivac } ® \text { Plus (Guangdong Academy of } \\
\text { Agricultural Sciences) }\end{array}$ & E. acervulina, E. maxima, E. tenella & Killed antigen of E. maxima gametocytes \\
\hline Eimeriavax® 4m (Bioproperties Pty) & E. acervulina, E. maxima, E. tenella, E. necatrix & Attenuated (precocious) \\
\hline Hipracox® Broilers (Laboratorios Hipra, SA) & $\begin{array}{l}\text { E. acervulina, E. maxima, E. tenella, E. praecox, } \\
\text { E. mitis }\end{array}$ & Attenuated \\
\hline Immucox® C1 (Vetech Laboratories) & E. acervulina, E. maxima, E. necatrix, E. tenella & Non-attenuated \\
\hline Immucox® C2 (Vetech Laboratories) & $\begin{array}{l}\text { E. acervulina, E. maxima, E. necatrix, E. tenella, } \\
\text { E. brunetti }\end{array}$ & Non-attenuated \\
\hline Immuner® Gel-Doc (Vacumas Inmuner) & E. acervulina, E. maxima, E. brunetti, E. tenella & Attenuated \\
\hline Inovocox® (Embrex Inc. and Pfizer) & E. acervulina, E. maxima, E. tenella & Non-attenuated \\
\hline Livacox® Q (BioPharm) & E. acervulina, E. maxima, E. necatrix, E. tenella, & $\begin{array}{l}\text { Attenuated (precocious, except E. tenella } \\
\text { (embryo-adapted) }\end{array}$ \\
\hline Livacox® T (BioPharm) & E. acervulina, E. maxima, E. tenella & $\begin{array}{l}\text { Attenuated (precocious, except E. tenella } \\
\text { (embryo-adapted) }\end{array}$ \\
\hline Paracox®-8 (Schering Plough Animal Health) & $\begin{array}{l}\text { E. acervulina, E. maxima, E. brunetti, E. mitis, E. } \\
\text { tenella, E. necatrix, E. praecox }\end{array}$ & Attenuated (precocious) \\
\hline Paracox®-5 (Schering Plough Animal Health) & E. acervulina, E. maxima, E. mitis, E. tenella & Attenuated (precocious) \\
\hline $\begin{array}{l}\text { Supercox® (Qilu Animal Pharmaceutical } \\
\text { Company) }\end{array}$ & E. acervulina, E. maxima, E. tenella & $\begin{array}{l}\text { Attenuated (precocious: E. tenella) non- } \\
\text { attenuated (E. acervulina, E. maxima) }\end{array}$ \\
\hline
\end{tabular}


Immucox ${ }^{\circledR}$ (Vetech Laboratories): Immucox is a live vaccine composed of wild-type Eimeria species that are drug-sensitive. Immucox is administered in a single dose via water or an edible gum (gel) at the hatchery, or on the farm at 1 to 4 days of age. The Immucox $^{\circledR}$ vaccine is of two types, the Immucox ${ }^{\circledR}$ for Chicken 1 (protecting broilers and roasters) and the Immucox ${ }^{\circledR}$ for Chicken 2 (protecting breeders and commercial layers). The Immucox ${ }^{\circledR}$ for Chicken I contains four species, namely $E$. acervulina, E. maxima, E. necatrix, and $E$. tenella, while the Immucox Chicken 2 contains five species, namely E. acervulina, E. brunetti, E. maxima, E. necatrix, and E. tenella.

Nobilis COX ATM $^{\otimes}$ (Intervet): This vaccine is tailored for application in broiler chickens, containing a mixture of four wild-type strains of Eimeria species. These strains are ionophore-resistant strains of $E$. acervulina, E. tenella, and two antigenically different strains of $E$. maxima. These ionophore-tolerant strains allow the use of an ionophore anticoccidial drug in the feed during the first 3 to 4 weeks, giving a chance for the immunity to be acquired for better prevention of coccidiosis outbreaks (Vermeulen et al., 2001). The Nobilis COX ATM ${ }^{\circledR}$ vaccine efficacy is not compromised during the application of ionophores for the control of Clostridium perfringens, the etiologic agent of necrotic enteritis in broilers.

Advent $^{\circledR}$ (Novus International): This is a vaccine for broilers used in hatchery spray cabinets, or via feed spray or drinking water. The Advent ${ }^{\circledR}$ vaccine differs from other live vaccines, in which the nonviable sporocysts are stained with ethidium bromide, allowing for a better control of the level of viable oocysts (Dibner et al., 2003). It contains a mixture of $E$. acervulina, E. maxima, and E. tenella. These strains are sensitive to commonly used anti-coccidial drugs.

Inovocox ${ }^{\circledR}$ (Embrex Inc. and Pfizer): This is a live oocyst broiler vaccine containing a mixture of $E$. acervulina, E. tenella, and two strains of E. maxima. It is administered in ovo on day 18 of incubation using an automated in ovo injection device (Inovoject System) (Weber \& Evans, 2003; Weber et al., 2004). The strains of coccidia included in the vaccine are sensitive to commonly used anticoccidial drugs.

\section{Attenuated vaccines}

The attenuated live vaccines do not include wild-type strains, claiming a higher safety in their applications on chicken. The following are the registered live attenuated vaccines:
Paracox ${ }^{\circledR}$ (Schering Plough Animal Health): The Paracox ${ }^{\circledR}$ has two types, the Paracox ${ }^{\circledR}-8$ (registered for use on breeders and layers), and the Paracox ${ }^{\circledR}-5$ (registered for its application on broilers). The Paracox $^{{ }-8}$ consists of precocious species of $E$. acervulina, E. maxima (2 strains), E. mitis, E. tenella, E. brunetti, E. praecox, and E. necatrix, eight strains that have the characteristics of short life cycle and reduced pathogenicity. The eight strains in this vaccine are drug sensitive. The Paracox ${ }^{\circledR}-8$ is administered via drinking water or feed spray, at an age of 1-9 days. The Paracox ${ }^{\circledR}-5$ contains four species, namely $E$. acervulina, E. maxima (2 strains), E. mitis, and E. tenella. The Paraco ${ }^{\circledR}-5$ is administered as a single dose at $1-3$ days of age, via hatchery spray, drinking water or feed spray.

Livacox ${ }^{\circledR}\left(\right.$ Biopharma): The Livacox ${ }^{\circledR}$ attenuated vaccine has two types, the Livacox ${ }^{\circledR} \mathrm{Q}$, tailored for use in layers and breeders, and the Livacox ${ }^{\circledR} \mathrm{T}$, for use in broilers. The Livacox ${ }^{\circledR} \mathrm{Q}$ contains a mixture of four species namely, E. acervulina, E. maxima, E. necatrix and an embryo-adapted E. tenella, while the Livacox ${ }^{\circledR}$ $T$ contains a mixture of only three species namely, $E$. acervulina, E. maxima, and an embryo adapted- $E$. tenella. Both the Livacox ${ }^{\circledR} \mathrm{Q}$ and Livacox ${ }^{\circledR} \mathrm{T}$ are administered in single dose at 1 to 10 days of age, through hatchery spray, drinking water or feed spray.

Since live vaccines contain more than one species, the evaluation of their efficacy differs from that used for anticoccidials. The new protocols for assessment of the efficacy of live vaccines are based mainly on growth rates of vaccinated birds challenged with the virulent strains. Another secondary criterion used in these polyvalent vaccine evaluations is the feed conversion ratio. Such experimental designs avoid the determination of the oocyst production and lesion score, following the controlled challenge with the virulent strains of Eimeria (Williams \& Catchpole 2000).

Adequate reproduction in the host of the attenuated Eimeria strains is important for the efficacy of the developed live vaccines. The wild-type strains included in the non-attenuated vaccines tend to have a higher reproductive potential. The main factors involved in the reproduction potential of Eimeria strains under field conditions are summarized in Table 2 by Chapman et al. (2002).

Attenuated vaccines develop faster than the nonattenuated vaccines due to their short life cycles; however, their fecundity or reproductive potential is lower, as shown in Table 3 (Shirley et al., 2005). Table 3 shows the consistent larger outputs in oocysts of parent compared to precocious strains of different 
Table 2 - Major factors that influence the reproduction of Eimeria under field conditions.

\begin{tabular}{|c|c|c|}
\hline Factor & Effect & $\begin{array}{l}\text { Oocyst } \\
\text { Accumulation } \\
\text { Trend }\end{array}$ \\
\hline Bird oocyts burden in litter & $\begin{array}{l}\text { Large initial number present in the litter results in earlier and higher number of oocysts } \\
\text { accumulating in litter }\end{array}$ & $\pi$ \\
\hline Chick density & $\begin{array}{l}\text { Higher densities increase the build-up of faeces and result in an increase in number of oocysts in the } \\
\text { litter }\end{array}$ & $\pi$ \\
\hline Litter condition & $\begin{array}{l}\text { Higher ammonia and lower oxygen levels eventually reduce oocyst survival. Moisture content affects } \\
\text { the sporulation of oocysts }\end{array}$ & ע \\
\hline Management & Chick dispersion spreads faeces and increase litter oocyst levels & $\pi$ \\
\hline Excystation & Increased Excystation rates increase the number of oocysts produced & $\pi$ \\
\hline Crowding & High fecundity results in "crowding " that reduces the reproductive potential of the parasite & y \\
\hline Interactions & Interaction between species may result in a reduction of reproductive potential & y \\
\hline Immunogenicity & Higher parasite immunogenicity reduces oocysts yield more rapidly & 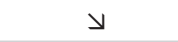 \\
\hline Susceptibility of birds & Greater innate susceptibility of birds to Eimeria increases oocysts yields & $\pi$ \\
\hline
\end{tabular}

Source: Chapman et al. (2002).

species of Eimeria. The crowding effect in nonattenuated lines, in the presence of limited epithelial cells and efficient cell mediated immunity, will result in reduced reproduction of oocysts, especially when chickens are exposed to high doses. Consequently, the lower fecundity of the attenuated lines is better for parasite reproduction, leading to enhanced immunity development.

The marked immunological diversity found among E. maxima species raises concerns about the efficacy of the developed vaccines against it. Vaccinating against one strain of $E$. maxima may not protect against the other E. maxima strains present in the field. Immunological relevance has been demonstrated experimentally with cross protection between strains ranging from 10 to $70 \%$, based on the oocyst output and lesion score (Smith et al., 2002). The inclusion of two strains of Eimeria maxima, representing extreme immunological diversity, seems indispensable (Shirley \& Bellatti, 1988).

\section{Subunit and recombinant vaccines}

Subunit vaccines are engineered proteins derived from the virulent Eimeria parasite. The identification of specific antigens in the Eimeria spp., at different stages of its life cycle that are capable of inducing protective immunity, is a necessary step in development of subunit vaccines. Recombinant proteins of both the protozoan surface and internal antigens were identified as candidates for such vaccines. The most widely

Table 3 - Reproduction of precocious lines in comparison to that of wild-type parent - Source: Shirley et al. (2005).

\begin{tabular}{|c|c|c|c|}
\hline Species & Strain & Output of oocysts (Millions) & $\begin{array}{l}\text { Percentage output compared to } \\
\text { relevant parent strain }\end{array}$ \\
\hline \multirow[t]{2}{*}{ E. acervulina } & HP & 1.1 & 7.7 \\
\hline & $\mathrm{H}$ (parent) & 14.3 & 100 \\
\hline \multirow[t]{2}{*}{ E. brunetti } & HP & 3.5 & 8.4 \\
\hline & $\mathrm{H}$ (parent) & 41.8 & 100 \\
\hline \multirow[t]{2}{*}{ E. maxima } & $C P$ & 1.6 & 4.1 \\
\hline & C(parent) & 39.3 & 100 \\
\hline \multirow[t]{2}{*}{ E. maxima } & MFP & 1.9 & 8.8 \\
\hline & MF(parent) & 21.6 & 100 \\
\hline \multirow[t]{2}{*}{ E. mitis } & HP & 0.7 & 2.6 \\
\hline & $\mathrm{H}$ (parent) & 27.0 & 100 \\
\hline \multirow[t]{2}{*}{ E. necatrix } & HP & 2.1 & 24.7 \\
\hline & $\mathrm{H}$ (parent) & 6.5 & 100 \\
\hline \multirow[t]{2}{*}{ E. praecox } & HP & 5.2 & 8.5 \\
\hline & $\mathrm{H}$ (parent) & 61.1 & 100 \\
\hline \multirow[t]{2}{*}{ E. tenella } & HP & 28.2 & 27.9 \\
\hline & $\mathrm{H}$ (parent) & 101.1 & 100 \\
\hline
\end{tabular}

Note: Doses of oocysts given were $2 \times 10^{2}$ for all species except E. brunetti $\left(1 \times 10^{2}\right)$ and E. tenella $\left(5 \times 10^{2}\right)$. Codes " $\mathrm{H}^{\prime \prime}$;"MF" and "C" refer to parent, virulent strains and addition of " $P$ " suffix refers to precocious lines. 
tested anticoccidial subunit vaccine candidates are listed in Blake \& Tomley (2014). The focus on surface proteins included mainly the invasive stages of Eimeria, namely sporozoites, merozoites, and gametocytes. These recombinant proteins induced an acceptable level of humoral and CMI immunities, that resulted until the present time in one commercial registered product, CoxAbic ${ }^{\circledR}$, documented by Wallach (1997). The $\mathrm{CoxAbic}^{\circledR}$ is an oil emulsion vaccine inducing maternally derived antibodies aimed at protecting the broiler progeny (Finger \& Michael, 2005; Ziomko et al., 2005). This is the only available recombinant commercial coccidiosis vaccine that transmits passive immunity through the yolk of hatching eggs to the progeny. The acquired immunity in the chicken breeders is developed against purified gametocyte antigens $230 \mathrm{kDa}, 82 \mathrm{KDa}$, and $56 \mathrm{KDa}$ of E. maxima that are present in this recombinant vaccine (Wallach, 1997). The immunization of the breeders by the mentioned gametocyte antigens is proven to protect their offspring from challenges with $E$. acervulina, E. maxima, and E. tenella, reducing oocyst output by $60-80 \%$, in comparison to similarly challenged offspring produced by breeders that were deprived of vaccination (Wallach, 1997).

A relevant limiting factor in the development of recombinant vaccines for protection against coccidiosis is the lack of information related to the nature of antigens responsible for the potent protective immunity against field strains. There is a great need for further investigation on the field Eimeria strainshost interaction, both at the cellular and molecular level, with the hope of the discovery of appropriate recombinant vaccines that can protect against the diversified prevalent field strains. The $E$. tenella genome project may be helpful in identifying the protective antigens in this parasite and their interaction with the host immune system (Shirley et al., 2007).

\section{DNA-based vaccines}

The DNA-based vaccines that could be developed in the future to protect against coccidiosis will adopt the technology of including in the product specific genes that encode for protective immunogenic proteins of the Eimeria. These genes are administered in conjunction with promoters and enhancers. In addition, vectors are ligated to these genes to ensure their penetration to inside the chicken cells, resulting in efficient translation of the protective antigenic proteins (Dalloul \& Lillehoj, 2006). These directions in research, towards the development of subunit, recombinant, and DNA-based vaccines, emerged in the last two decades as a result of avoiding in the future the use of live vaccines, which, if improperly administered, will likely cause coccidiosis outbreaks. These sensitive issues about the safety of live Eimeria spp. vaccines evoked persistent arguments among scientists of their degree of benefits, requiring a dwelling in the coming section of this review about their advantages and disadvantages.

\section{ADVANTAGES AND DISADVANTAGES OF LIVE EIMERIA SPP. VACCINES}

\section{Advantages of live Eimeria spp.vaccines}

Live Eimeria vaccines are a practical and important alternative to the exclusive use of coccidiostats that may leave residues in poultry products for human consumption. A number of studies indicated that Eimeria vaccines provide a protection level against coccidiosis in broilers similar to that obtained by anticoccidial programs; actually, the vaccine administration through a gel at 1 day of age proved to ensure a synchronous exposure and homogeneous protection among the birds (Jenkins et al., 2012). The use of live vaccines leads to a replacement of the drugresistant strains of coccidia in the broiler house with drug-susceptible vaccine strains. This increases the efficacy of anticoccidial drugs that are used in rotation programs with vaccines (Williams, 1998). In addition, live vaccines allow the gradual buildup of solid immunity, and provide protection against subsequent coccidial challenges, associated with an acceptable safety and minimal tissue damage, especially with the use of attenuated vaccines (Williams, 1994).

\section{Disadvantages of Eimeria spp. vaccines}

The produced oocysts of Eimeria spp. that are included in live vaccines have a known tendency of losing their infectivity to the host with prolonged storage periods, thus compromising their efficacy in inducing an acquired immunity in the birds (Jeston et al., 2002). Moreover, vaccine oocyst production is costly, since their propagation is restricted to living chickens, and no cell line is yet available for their multiplication. In addition, the antigenicity of the coccidial strains can vary according to geographical locations. Thus, it is important to characterize at the molecular level the local populations of the coccidial parasite, and to determine the ability of the available live vaccines to protect against the prevalent field strains (Danforth, 1998). Moreover, there is a risk of introducing undesirable Eimeria species present in the live vaccines 
into the farm environment. This requires the tailoring of Eimeria spp. vaccines that contain oocysts of the species that are matching in its antigenicity to the ones that are prevalent in a certain geographical area. The live vaccines carry the risk of causing economic losses when administered to immune-suppressed chickens (Anderson, 1977). The improper administration of the live Eimeria spp. vaccines may result in asynchronous exposure to the birds, with significant variation in the number of ingested oocysts, resulting in unacceptable homogeneity of their immunities, and a possibility of coccidiosis outbreak in birds with low immune responses to protective antigens of Eimeria (Chapman et al., 2002).

\section{CONTROL OF COCCIDIOSIS BY HOLISTIC APPROACHES OF NATURAL PRODUCTS}

Anticoccidial drugs were used effectively over the past 50 years. Their use resulted in a rapid growth of poultry industry and the affordable poultry products to the consumers. However, the increasing resistance to Eimeria species has stimulated the efforts to search for alternative control measures (Abbas et al. 2012; Kim et al. 2013; Ahmad et al. 2014). Holistic approach is currently searched and it is attempted by the application of herbal products for control of coccidiosis. The main researched herbs and their studied anticoccidial properties are shown below.

\section{Artemisinin}

Artemisinin is a Chinese herbal extract from Artemisia annua (annual wormwood), and A. sieberi. Artemisinin has an antimalarial effect in humans; its mode of action is attributed to the fact that artemisinin has an endoperoxide group that act against the parasite by generating highly reactive free oxygen radicals (oxidative stress) (Yang et al., 1994). Oh et al. (1995) was the first to report that $A$. annua extracts have an anticoccidial activity against $E$. tenella, as deduced from the herb's impact on improved weight gain, improved feed conversion and reduced lesion scores. Dried Artemisia annua leaves were evaluated for their anticoccidial activity in poultry as feed additives. The leaves were added to the poultry diet at a $5 \%$ concentration for a period of 3 weeks equivalent to $17 \mathrm{ppm}$ of pure artemisinin. This supplemented diet resulted in a significant protection against lesions of $E$. tenella in poultry. When pure artemisinin was added to the feed for a period of 4 weeks at different concentrations of $2,8.5$ and $17 \mathrm{ppm}$, it was able to significantly reduce the oocysts output from single and dual spp. infection by E. tenella and Eimeria acervulina (Allen et al., 1997; Bozkurtet al., 2013). Similar study by Arab et al. (2006) showed the protective activity of artemisinin against $E$. tenella and $E$. acervulina, but not against E. maxima.

\section{Betaine}

The beneficial effect on performance, by added sugar beet (Beta vulgaris) to livestock feed, had been recognized for a long time. One of the ingredients of sugar beet is betaine, which is a bipolar electrolyte, choline analogue, and methyl donor. Betaine protects cells against osmotic stress, stabilizes cell membrane, and ensures normal metabolic activity in cells (Ko et al., 1994). Coccidiosis might cause diarrhea and dehydration resulting in osmotic stress; this stress is enhanced with ionophorous anticoccidials such as salinomycin. An osmoprotectant might therefore give benefits on performance parameters when used with ionophores. Augustine et al. (1997) indicated a positive effect on performance when feeding in combination, the salinomycin (66ppm) and betaine $(0.15 \%)$, to birds infected with a mixture of $E$. acervulina, E. maxima and $E$. tenella, resulting in better weight gain and feed efficiency.

\section{Echinacea species (purple coneflower, American coneflower)}

All species of Echinacea are herbaceous, perennial plants of the family Asteraceae, one of the largest families of flowering plants. Echinacea is considered one of the top 10 species of herbs known for their wound-healing and disease-resistance properties (Miller \& Yu, 2004). Echinacea is native to Central and Southwestern America. Echinacea consists of nine spp., three of which (Echinacea angustifolia, Echinacea pallida, and Echinacea purpurea) have been used medicinally in the United State and Europe, and are introduced to other countries due to the increased interest in alternative herbal medicine. Annual sales of Echinacea product were estimated at 300 billion dollars in the USA alone, including hundreds of preparations that are mostly used as remedies to treat cold, without the need for physician's prescription.

Echinacea is used for the treatment of the common cold and upper respiratory tract infections in humans, helping in reduction of the severity and duration of the cold symptoms (Caruso \& Gwaltney, 2005). It also has many other pharmacological activities, including anti-inflammatory and wound-healing properties 
(Speroni. et al., 2002; Raso et al., 2002). Furthermore, it is proven to enhance the immune response against tumor growth (Currier \& Miller, 2002).

Echinacea activates the innate immune response through macrophage activation (Goel et al., 2002), macrophage-derived cytokine production, and activation of polymorphonuclear leukocytes and natural killer cells (Currier \& Miller, 2001), thus acting as an immunostimulant. Phagocytic activity of alveolar macrophages in rats was specifically activated by the alkamide component of Echinacea pupurea (Goel et al. 2002). Polysaccharide constituent of the plant Echinacea purpurea were found to enhance phagocyte activity and to inhibit growth of Candida albicans and Listeria monocytogenes in mice (Roesler et al., 1991). Moreover, certain standardized preparations of Echinacea purpurea were proven to have potent antimicrobial and antiviral activity in humans (Hudson, 2012).

Barbour et al. (2000) reported that a dose of $0.147 \%$ supplementation of Echinacea pupurea roots to broiler feeds induced immunopotentiation, reduced immunosuppression caused by Infectious Bursal Disease (IBD), and lowered infectivity by Salmonella Enteritidis. Other studies suggested a presence of modulation of the adaptive immune response due to Echinacea treatment in mice (Zhai et al., 2007). Freier et al. (2003) showed an enhancement of humoral and innate immune responses in mice using an extract of E. purpurea. Other studies showed increased humoral response associated with an increasing antigenspecific immunoglobulin production, due to treatment with Echinacea and other herbs (Bodinet et al., 2002). Morazzoni et al. (2005) reported that $E$. angustifolia extract stimulated T-cells function in murines by increasing the production of IFN-gamma. However, results concerning its benefits are conflicting, since most studies have used different preparations, thus not permitting the implementation of meta-analysis on these documented research publications to reach solid conclusions (Percival, 2000; Islam \& Carter, 2005).

Echinacea species are harvested for their roots, flower heads, seeds, or are pressed as juice of the whole plant. The main pharmaceutical components of Echinacea are caffeic acid derivatives (cichoric acid and echinacoside), alkamides, polysaccharides, cinnamic acids, glycoproteins, flavonoids, essential oils, and phenolic compounds (Liu et al., 2007). The medicinal activity of this herb is due to a combination of cichoric acid, alkylamides, and polysaccharides, which are present in all of the three species ( $E$. angustifolia, $E$. pallida, and E. purpurea), but in various amounts. It is proven that a purified phytochemical from these species does not give the same immunological activity as that resulting from the whole plant extract. The medicinal activity seems to depend on several active compounds present in the herb, working together in a synergistic manner (Randolph et al., 2005). For this reason, using a mixture of Echinacea plant extracts resulted in a higher efficacy than using an extract from one plant alone (Bodinet et al., 2002).

Studies on Echinacea proved its non-toxic nature at relatively high doses (Mengs et al., 1991). Overall adverse effects are rare, and are mainly associated with gastrointestinal and skin related problems such as nausea, abdominal pain, diarrhea, itch, and rash (Huntley et al., 2005). There are a few reports related to the therapeutic potential of Echinacea on horses (O'Neill et al., 2002), pigs (Stahl et al., 1990), cattle (Schuberth et al., 2002), and three reports on its possible use in poultry diseases (Barbour et al., 2000; Allen, 2003; Böhmer, 2009). Allen (2003) studied the effect of the addition of ground root preparations of Echinacea purpurea (EP), at concentrations of $0.1 \%$ and $0.5 \%$ into broiler starter feed, and an administration period of 2 weeks, on the development of immunity to a live vaccine (half strength dose of Immucox ${ }^{\circledR}$ vaccine at day 1), followed by a challenge with mixed infection of $E$. acervulina, E. maxima, $E$. tenella and $E$. necatrix. The weight gains before challenge were improved by the EP treatment compared with that obtained with live-vaccination alone. The EP protected the challenged broilers at age of 28 days, improving their weight gain and reducing the gross lesions. Allen (2003) noted that EP alone, without vaccination, had little effect on sustaining weight gain after challenge, suggesting that the EP's action is dependent on presence of vaccinal antigens, and that its potential use as an adjuvant, requires a concurrent administration of live vaccine. Böhmer (2009) reported an increase in laying hen lymphocyte counts due to treatments for five consecutive days with Echinacea juice, resulting in elevated Newcastle titers when the treatment was applied for only two consecutive days. Live performance was not affected and the phagocytic cells were suppressed due to two and five consecutive days of treatment. Phagocytosis of granulocytes was considerably reduced in hens and was thought to be due to the high alkamid concentrations used in the preparation. Alkamids are known to augment phagocytosis; however, a low dose 
of alkamids seems necessary for this augmentation. The author concluded that, two days- stimulation by Echinacea juice is adequate to increase the immune response in layers. Based on the available information of intermittent application of Echinacea juice, EP juice showed an enhancement of performance and immunity in Ross breed-broilers. This finding is based on an experiment, using Ross breed-broilers administered orally the EP juice for three consecutive days, and repeated the administration for three times during the 35 days of rearing the birds. Moreover, EP juices induced a positive effect on cardiac muscles of fast growing broilers (Zahid, 2009).

\section{Aloe vera}

Aloe vera has been cited in the literature for its curative and therapeutic properties, having more than 75 biologically active compounds in it. The Aloe vera immunostimulatory effect in broilers infected with Eimeria species was reported by Akhtar et al. (2012). Aloe vera extracts enhanced the humoral and cellular immune responses in chickens. It stimulated the macrophages-phagocytic activity, cytokines production, and induced better antibody production. Furthermore, Aloe vera reduced oocyst output and lesion scores. The results of this work were in agreement with those of Yim et al. (2011), who tested the effects of Aloe vera against E. maxima infection. These researchers showed that oocyst shedding and lesion scores were significantly reduced in the Aloe vera treated groups; however, no data were presented in relation to production performance of the chicken included in their experimental design.

\section{Azadirachta indica (Neem)}

This plant is commonly found in African and Asian countries, and it is known for its therapeutic effects against various infectious diseases, including coccidiosis. The neem fruit, at an inclusion rate of 150 $\mathrm{g} / 50 \mathrm{~kg}$ feed, had an anticoccidial activity against $E$. tenella, as concluded from oocyst output and mortality in broilers (Tipu et al., 2002). The water extract of neem leaves has also an anticoccidial activity against $E$. tenella comparable to that obtained by Baycox drug (Toulah et al. 2010). Neem had an anticoccidial effect against a mixed infection by different species of Eimeria. This effect was comparable to that produced by Amprolium drug (Biu et al., 2006). Neem also enhanced cellular immune response and antibody production (Biu et al., 2006). Further studies on the mode of action and dose-related adverse effects of neem on birds, because its bitterness may affect feed intake, warrants further investigation.

\section{Emblica officinalis}

Emblica officinalis is commonly known as amla, and it is used widely in Chinese herbal medicine. A very recent study indicates that amla-derived tannins have an immuno-stimulatory effect against a mixed infection of Eimeria at doses of $0.5,0.75$, and $1 \mathrm{mg} / \mathrm{kg}$ body weight as measured by improved weight gains, and decreased oocyst counts and lesion scores (Kaleem et al., 2014).

\section{Mushrooms and their extracts}

Mushroom extracts have been increasingly sold as dietary supplements for their ability to enhance the immune system and promote health (Garcia et al., 1998). Mushroom extracts have anti-tumor properties. Unfortunately, their potential use could lead to exposure to toxic heavy metals, such as arsenic, lead, cadmium, and mercury, and to radioactive contamination with 137Cs (Borchers et al., 2004). Guo etal. (2004) reported the positive effects of polysaccharide extracts from two mushrooms, namely Lentinus edodes and Tremella fuciformis, and from a herb known as Astragalus membranaceus. The impact of the polysaccharides on cellular and humoral immunity of chickens infected with Eimeria tenella was evaluated. The experimental design aimed at investigating the effects of these polysaccharide extracts, which were supplemented in the feed for 1 week to chickens ranging from 7 to 14 days of age, at a level of $1 \mathrm{~g} / \mathrm{kg}$ diet, in conjunction with administration of live-attenuated Eimeria vaccine. The results of this trial on unchallenged birds showed a better growth in immunized and treated birds as compared to the immunized and un-treated ones. However, when challenged with E. tenella, birds treated with the extract showed similar lesion score and lower oocysts output than birds that were only vaccinated.

Dalloul et al. (2006) reported a novel immunopotentiating effect of a lectin, extracted from the mushroom Fomitella fraxinea, and injected in 18-day-old embryos. The extracted lectin protected broilers inoculated with E. acervulina at one week post hatch from weight loss, and was associated with significant reduction in oocyst output as compared to non-injected embryos. These researchers suggested that lectins act as immunopotentiators of innate immune response, and could be used as an alternative control to coccidiosis. 


\section{PREBIOTICS AND PROBIOTICS}

The prebiotic mannan oligosaccharide (MOS), derived from the cell wall of the yeast Saccharomyces cerevisiae, was used widely in poultry feeds to promote poultry gut health and performance. The mode of action of MOS differs from that of other prebiotics, due to their ability to bind to receptors in the intestinal wall, preventing pathogens to colonize the intestinal tract (Spring et al., 2000). El-Musharaf et al. (2006) showed that dietary MOS at $1 \mathrm{~g} / \mathrm{kg}$ was able to reduce the number of schizonts resulting from an infection by 3500 or 5000 sporulated oocysts of E. tenella. However, this study showed that the MOS results in an insignificant decrease in fecal oocyst counts, severity of cecal lesions, and growth performance.

Another experiment by El-Musharaf et al. (2007) showed that the administration of MOS at a concentration of $10 \mathrm{~g} / \mathrm{kg}$ diet reduces the number of oocysts per gram of feces (OPG) of birds that were infected at day one with a mixture of $E$. acervulina, $E$. maxima, and E. tenella, at doses of 900,570 and 170 of sporulated oocysts respectively, when compared to infected controls deprived of MOS. In addition, a significant reduction of Eimeria acervulina-induced lesions by MOS was documented ( $p<0.05)$; however, this treatment did not reduce the lesions induced by $E$. maxima and E. tenella.

McCann et al. (2006) reported that a supplementation of MOS at $0.5 \mathrm{~g} / \mathrm{kg}$ and tannins at 0.5 $\mathrm{g} / \mathrm{kg}$ diet, individually or combined, did not reduce the severity of the infection by E. acervulina, E. maxima, and $E$. tenella at sporulated oocyst doses of 15,000 and 50,000 . Further studies must be carried out to include different concentrations of MOS and different oocyst doses challenging the birds at different ages, in order to conclude about the benefit of MOS in control of coccidiosis in poultry.

The use of probiotics for poultry was proposed in order to competitively exclude the colonization of intestinal pathogens, especially after the European Commission banned the inclusion of antibiotics in poultry feeds. Probiotics are effective against a variety of pathogens, including Clostridium perfringens (La Ragione et al., 2004), which is a secondary infectious agent that flourishes in the presence of injuries resulting from Eimeria spp. Probiotics promote growth, feed efficiency, egg production and egg mass in poultry (Jernigan et al., 1985; Jin et al., 1997). Probiotics are effective against Eimeria due to their proven ability to reduce its invasion and development. Lactobacillus- supplemented feed enhanced local cell mediated immunity in E. acervulina-infected broilers (Dalloul. et al. 2005). The co-administration of probiotic with Eimeria vaccination resulted in improved performance compared to vaccination alone (Klein 2009).

Last but not least, the work on the prebiotics mannan oligosaccharides (MOS) and Lactobacillus are not yet conclusive as to their anti-coccidial effect, and further investigations are needed.

\section{CONCLUSIONS/FUTURE DIRECTIONS}

This review presented approaches targeting the replacement of coccidiostat application in poultry production as alternative controls. This review discussed the impacts of management, vaccines, natural products, prebiotics and probiotics, individually or in combination, on the control of different species of Eimeria causing coccidiosis in chickens.

The management of the litter and ventilation, providing the proper moisture level in order to prevent very dry litter, has been proven reduce oocyst sporulation and multiplication.

The developed and commercialized vaccines are protective against coccidiosis; however, the vaccination is very sensitive to management, and any failure during the administration of vaccines may cause vaccine failure or even an outbreak by the live vaccine strains. In addition, the presence of diversity in the same Eimeria spp. strains could lead to their escape from the vaccine response. Therefore, more research is needed on safer recombinant vaccines that can cover a wider range of these coccidial strains. The holistic herbal approach for the replacement of coccidiostats seems promising, including the research related to the Echinacea and neem herbs.

\section{ACKNOWLEDGEMENTS}

The support of the distinct proposal by the Deanship of Scientific Research (DSR), at King Abdulaziz University, Jeddah, is appreciated. The authors acknowledge with thanks the DSR technical and financial support.

\section{FINANCIAL SUPPORT}

The financial support of EWABO Co., Germany, is appreciated, which helped in supporting the graduate work of Mrs. Danielle B. Ayyash, who concluded her thesis work on the subject of holistic herbal approach for control of Eimeria spp. in chickens. 


\section{REFERENCES}

Abbas RZ, Colwell DD, Gilleard J. Botanicals: an alternative approach for the control of avian coccidiosis.World's Poultry Science Journal 2012;68:203-215.

Ahmad M, Kamran SH, Mobasher A. Protective effect of crude Curcuma longa and its methanolic extract in alloxanized rabbits. Pakistan Journal of Pharmaceutical Sciences. 2014;27:121-128.

Akhtar M, Hai A, Awais MM, lqbal Z, Muhammad F, ulHaq A, Anwar MI. Immunostimulatory and protective effects of Aloe vera against coccidiosis in industrial broiler chickens. Veterinary Parasitology 2012;186:170-177.

Allen PC. Dietary supplementation with Echinacea and development of immunity to challenge infection with coccidia. Parasitology Research 2003:91:74-78

Allen PC, Fetterer RH. Recent advances in biology and immunobiology of Eimeria species and in diagnosis and control of infection with these coccidian parasites of poultry. Clinical Microbiology Reviews 2002;15:58-65

Allen PC, Lydin J, Danforth HD. Effects of components of Artemisia annua on coccidia infections in chickens. Poultry Science 1997;76:1156-1163.

Anderson WI, Reid WM, Lukert PD, Fletcher OJ Jr. Influence of infectious bursal disease on the development of immunity to Eimeria tenella. Avian Diseases 1977;21:637-641.

Arab HA, Rahbari S, Rassouli A, Moslemi MH, Khosravirad F. Determination of artemisinin in Artemisia sieberi and anticoccidial effects of the plant extracts in broiler chickens. Tropical Animal Health and Production 2006;38:497-503.

Augustine PC, Mcnaughton JL, Virtanen E, Rosi L. Effect of betaine on the growth performance of chicks inoculated with mixed cultures of Avian Eimeria species and on invasion and development of Eimeria tenella and Eimeria acervulina in vivo and in vitro. Poultry Science 1997:79:802-809

Barbour EK, Husseini SS, Eid A, Saker W, Hamadeh SK. A holistic approach for growth promotion, protection against Salmonella Enteritidis, and immunopotentiation against infectious bursal disease virus in broiler chickens. Journal of the American Veterinary Medical Association 2000;19:19-24.

Belli SI, Smith NC, Ferguson DJP. The coccidian oocyst: a tough nut to crack! Trends in Parasitology 2006;22:416-423.

Biu AA, Yusuf SD, Rabo JS. Use of neem (Azadirachta indica) aqueous extract as a treatment for poultry coccidiosis in Borno State, Nigeria. African Scientist 2006;7:147-153.

Blake DP, Tomley FM. Securing poultry production from the ever-present Eimeria challenge. Trends in Parasitology 2014;30:12-19.

Bodinet $C$, Lindequist $U$, Teuscher $E$, Freudenstein J. Effect of an orally applied herbal immunomodulator on cytokine induction and antibody response in normal and immunosuppressed mice. Phytomedicine 2002:9:606-613

Böhmer BM, Salisch H, Paulicks BR, Roth FX. Echinacea purpurea as a potential immunostimulatory feed additive in laying hens and fattening pigs by intermittent application. Livestock Science 2009;122:81-85.

Borchers AT, Keen CL, Gershwin ME. Mushroom, tumors, and Immunity: An Update. Experimental Biology and Medicine 2004;229:393-406.

Bozkurt M, Giannenas I, Küçükyilmaz K, Christaki E, Florou-Paneri P. An update on approaches to controlling coccidia in poultry using botanical extracts. British Poultry Science 2013:54:713-727.
Caruso TJ, Gwaltney JM Jr. Treatment of the common cold with Echinacea: a structured review. Clinical Infectious Diseases 2005;40:807-810.

Chapman HD, Cherry TE, Danforth HD, Richards G, Shirley MW, Williams RB. Sustainable coccidiosis control in poultry production: the role of live vaccines. International Journal for Parasitology 2002;32:617-629.

Chapman HD. Drug resistance in avian coccidia (a review). Veterinary Parasitology 1984;15:11-27.

Chapman HD. Biochemical, genetic and applied aspects of drug resistance in Eimeria parasites of the fowl. Avian Pathology 1997;26:221-244.

Chapman HD. The development of immunity to Eimeria species in broilers given anticoccidial drugs. Avian Pathology 1999a;28:155-162.

Chapman HD. Anticoccidial drugs and their effects upon the development of immunity to Eimeria infections in poultry. Avian Pathology 1999b;28:521-535.

Conway DP, Mckenzie ME. Poultry coccidiosis: diagnostic and testing procedures. 3rd ed. Ames: Blackwell Publishing Professional; 2007.

Cuckler AC, Malanga CM. Studies on drug resistance in coccidia. Journal of Parasitology 1955;41:302-311.

Currier NL, Miller SC. Echinacea purpurea and melatonin augment naturalkiller cells in leukemic mice and prolong lifespan. Journal of Alternative and Complementary Medicine 2001;7:241-245.

Currier NL, Miller SC. The effect of immunization with killed tumor cells, with/without feeding of Echinacea purpurea in an erythroleukemic mouse model. Journal of Alternative and Complementary Medicine 2002:8:49-58

Dalloul RA, Lillehoj H.S. Poultry coccidiosis: recent advancement in control measures and vaccine development. Expert Review of Vaccines 2006:5:143-163.

Dalloul RA, Lillehoj HS, Lee JS, Lee SH, Chung KS. Immunopotentiating effect of a Formitella fraxinea-derived lectin on chicken immunity and resistance to coccidiosis. Poultry Science 2006;85:446-451.

Dalloul RA, Lillehoj HS, Shellum TA, Doerr JA. Induction of local protective immunity to Eimeria acervulina by Lactobacillus-based probiotic. Comparative Immunological Microbiological and Infectious Diseases 2005:28:351-361

Danforth HD. Use of live oocyst vaccines in the control of avian coccidiosis: experimental studies and field trials. International Journal for Parasitology 1998;28:1099-1109.

Dibner JJ, Pfannenstiel MA, Kitchell ML, Knight CD. Importance of oocyst viability testing for coccidiosis vaccines [special supplement coccidiosis, 4]. In: van der Sluis W, editor. World poultry. Amsterdam: Elsevier; 2003. p. $11-12$

Elmusharaf MA, Bautista $V$, Nollet L, Beynen AC. Effect of a mannaoligosaccharide preparation on Eimeria tenella infection in broiler chickens. International Journal of Poultry Sciences 2006;5:583-588.

Elmusharaf MA, Peek HW, Nollet L, Beynen AC. The effect of an in-feed manna oligosaccharide preparation (MOS) on a coccidiosis infection in broilers. Animal Feed Science and Technology 2007;134:347-354

Finger A., Michael A. Maternal protection against Eimeria challenge of CoxAbic ${ }^{\circledast}$ vaccinated chickens. Proceedings of the 9th International Coccidiosis Conference; 2005; Foz do Iguassu, Paraná. Brasil. p. 146.

Freier DO, Wright K, Klein K, Voll D, Dabiri K, Cosulich K, et al. Enhancement of the humoral immune response by Echinacea purpurea in female Swiss mice. Immunopharmacology and Immunotoxicology 2003:25:551-560 


\section{A Review of Approaches Targeting the Replacement of Coccidiostat Application in Poultry Production}

Garcia MA, Alonso J, Fernandez Ml, Melgar MJ. Lead content in edible wild mushrooms in Northwest Spain as indicator of environmental contamination. Archives of Environmental Contamination and Toxicology 1998;34:330-335

Goel V, Chang C, Slama JV, Barton R, Bauer R, Gahler R, et al. Alkylimides of Echinacea purpurea stimulate alveolar macrophage function in normal rats. International Immunopharmacology 2002;2:381-387.

Graat EA, van der Kooij E, Frankena K, Henken AM, Smeets JF, Hekerman MT. Quantifying risk factors of coccidiosis in broilers using on-farm data based on a veterinary practice. Preventive Veterinary Medicine 1998;33:197-308.

Grumbles LC, Delaplane JP, Higgins TC. Continuous feeding of low concentrations of sulfaquinoxaline for the control of coccidiosis in poultry. Poultry Science 1948;27:605-608.

Guo FC, Kwakkel RP, Williams BA, Paramentier HK, Li WK, Yang ZQ, et al. Effects of mushroom and herb polysaccharides on cellular and humoral immune responses of $E$. tenella-infected chickens. Poultry Science 2004;83:1124-1132.

Hudson JB. Applications of the phytomedicine Echinacea purpurea (Purple Coneflower) in infectious diseases. Journal of Biomedicine and Biotechnology 2012;2012:769896.

Huntley AL, Thompson Coon J, Ernst E. The safety of herbal medicinal products derived from Echinacea species:a systematic review. Drug Safety 2005;28:387-400

Islam J., Carter R. Use of Echinacea in upper respiratory tract infection. Southern Medical Journal 2005;98:311-318.

Jenkins MC, Parker C, Klopp S, O'Brien C, Miska K, Fetterer R. Gel-Bead Delivery of Eimeria oocysts protects chickens against coccidiosis. Avian Disease 2012;56:306-309.

Jernigan MA, Miles RD, Arafa AS. Probiotics in poultry nutrition - a review. World's Poultry Science Journal 1985;41:99-107.

Jeston PJ, Blight GW, Anderson GR, Molloy JB, Jorgensen WK. Comparison of infectivity of Eimeria tenella oocysts maintained at 4,12 or $28^{\circ} \mathrm{C}$ up to 10 months. Australian Veterinary Journal 2002;80:91-92.

Jin LZ, Ho YW, Abdullah N, Jalaludin S. Probiotics in poultry:modes of action. World's Poultry Science Journal 1997;53:351-368.

Kaleem QM, Akhtar M, Awais MM, Saleem M, Zafar M, lqbal Z, et al. Studies on Emblica officinalis derived tannins for their immunostimulatory and protective activities against coccidiosis in industrial broiler chickens. The Scientific World Journal 2014;2014:1-10.

Kim DK, Lillehoj HS, Lee SH, Jang SI, Lillehoj EP, Bravo D. Dietary Curcuma longa enhances resistance against Eimeria maxima and Eimeria tenella infections in chickens. Poultry Science 2013;92:2635-2643.

Klein A. Effects of probiotic administration during Coccidiosis vaccination on performance and lesion development in broilers [dissertation]. Texas: A \& M University; 2009.

Ko R, Smith LT, Smith GM. Glycine betaine confers enhanced osmotolerance and cryotolerance on Listeria monocytogenes. Journal of Bacteriology 1994;176:426-431.

La Ragione RM, Narbad A, Gasson MJ, Woodward MJ. In vivo characterization of Lactobacillus johnsonii Fl9785 for use as a defined competitive exclusion agent against bacterial pathogens in poultry. Journal of applied bacteriology 2004;38:197-205.

Levine PP. The effect of sulfanilamide on the course of experimental avian coccidiosis. Cornell Vet 1939;29:309-320.
Liu YC, Zeng JG, Chen BO, Yao SZ. Investigation of phenolic constituents in Echinacea purpurea grown in China. Planta Medica 2007;73:16001605.

McCann MEE, Newell E, Preston C, Forbes K. The use of Mannanoligosaccharides and/or Tannin in broiler diets. International Journal of Poultry Sciences 2006:5:873-879.

McDougald LR, Reid MW. Susceptibility of broilers to coccidiosis following early coccidiostat withdrawal. Poultry Science 1971;50:1164-1170.

Mengs U, Clare CB, Poiley JA. Toxicity of Echinacea Purpurea-Acute, subacute and genetoxicity studies. Drug Research 1991;41:1076-1081.

Miller SC, Yu He-Ci. Echinacea: the genus Echinacea. BocaRaton: CRC Press; 2004

Morazzoni P, Cristoni A, Di Pierro F, Avanzini C, Ravarino D, Stornello $S$, et al. In vitro and in vivo immune stimulating effects of a new standardized Echinacea angustifolia root extract (PolinaceaTM). Fitoterapia 2005;76:401-411.

O'Neill W, McKee S, Clark AF. Immunological and haematinic consequences of feeding a standardized Echinacea (Echinacea augustifolia) extract to healthy horses. Equine Veterinary Journal 2002;34:222-227.

Oh HG, Youn HG, Noh HJ, Jang JW, Kang YB. Anticoccidial effects of artemisin on the Eimeria tenella. Korean Journal Veterinary Research $1995 ; 35: 123-130$

Peek HW, Landman WJ. Higher incidence of Eimeria spp. field isolates sensitive for diclazuril and monensin associated with the use of live coccidiosis vaccinating with Paracox ${ }^{\mathrm{TM}_{-} 5}$ in broiler farms. Avian Diseases 2006;50:434-439.

Percival SS. Use of Echinacea in medicine. Biochemical Pharmacology 2000;60:155-158

Randolph RK, Gellenbeck K, Stonebrook K, Brovelli E, Qian Y, Bankaitis-Davis $D$, et al. Regulation of human immune gene expression as influenced by a commercial blended Echinacea product: preliminary studies. Experimental Biology and Medicine (Maywood) 2005;228:1051-1056.

Raso GM, Pacilio M, Di Carlo G, Esposito E, Pinto L, Meli R. In-vivo and in-vitro anti-inflammatory of Echinacea purpurea and Hypericum perforation. Journal of Pharmacy and Pharmacology 2002;54:1379 1383.

Razmi GR, Kalideri GA. Prevalence of subclinical coccidiosis in broilerchicken farms in the municipality of Mashhad, Khorasan, Iran. Preventive Veterinary Medicine 2000;44:247-253.

Roesler J, Stienmueller C, Kiderlen A, Emmendorffer A, Wagner H, LohmannMatthes ML. Application of purified polysaccharides from cell cultures of the plant Echinacea purpurea to mice mediates protection against systemic infections with Listeria monocytogenes and Candida albicans. International Journal of Immunopharmacology 1991;13:27-37.

Schuberth HJ, Riedel-Caspari G, Leibold W. Flow cytometric testing of immunological effects of a phytomedicinal combination (equimun) and its compounds on bovine leucocytes. Journal of Veterinary Medicine Series A-Physiology Pathological Clinical Medicine 2002;49:291-298

Shirley MW, Bellatti MA. Live attenuated coccidiosis vaccine:selection of a second precocious line of Eimeria maxima. Research in Veterinary Science 1988:44:25-28.

Shirley MW, Bushell AC, Bushell JE, McDonald V, Roberts B. A live attenuated vaccine for control of avian coccidiosis:trials in broiler breeders and replacement layer flocks in the United Kingdom. Veterinary Record 1995; 137:453-457. 
Shirley MW, Smith AL, Blake DP. Challenges in the successful control of the avian coccidia. Vaccine 2007; 25:5540-5547.

Shirley MW, Smith AL, Tomley FM. The biology of avian Eimeria with an emphasis on their control by vaccination. Advances in Parasitology 2005;60:285-330.

Smith AL, Hesketh P, Archer A, Shirley MW. Antigenic diversity in Eimeria maxima and the influence of host genetics and immunization schedule on cross-protective immunity. Infection and Immunity 2002;70:24722479.

Speroni E, Govoni P, Guizzardi S, Renzulli C, Guerra MC. Anti-inflammatory and cicatrizing activity of Echinacea pallida Nutt root extract. Journal of Ethnopharmacology 2002;79:265-2672

Spring P, Wenk C, Dawson KA, Newman KE. The effects of dietary mannanoligosaccharides on the cecal parameters and concentration of enteric bacteria in the caeca of salmonella-challenged broiler chicks. Poultry Science 2000;79:205-211.

Stahl M, Reifenberg K, Okpanyi S, Losch U. Porcine granulocyte functions: evaluation and modulation. Journal of Veterinary Medicine 1990;37:261-267.

Tipu MA, Pasha TN, Ali Z. Comparative efficacy of salinomycin sodium and neem fruit (Azadirachta indica) as feed additive anticoccidials in broilers. International Journal of Poultry Sciences 2002;1:91-93.

Toulah FH, Ismeel HA, Khan S. Effect of treatment with Neem (Azadirachta indica) compared with Baycox drug on the caecum of chicken experimentally infected with Eimeria tenella. Journal of the Egyptian Society of Parasitology 2010;40:93-106.

Tsuji N, Kawazu S, Ohta M, Kamio T, Isobe T, Shimura K, et al. Discrimination of eight chicken Eimeria species using the two-step polymerase chain reaction. Journal of Parasitology 1997;83:966-970.

Vermeulen AN, Schaap DC, Schetters TP. Control of coccidiosis in chickens by vaccination. Veterinary Parasitology 2001;100:13-20.

Vrba V, Poplstein M, Pakandl $M$. The discovery of the two types of small subunit ribosomal RNA gene in Eimeria mitis contests the existence of E. mivati as an independent species. Veterinary Parasitology 2011;183:47-53.

Waldenstedt L, Elwinger K, Lunden A, Thebo P, Uggla A. Sporulation of Eimeria maxima oocysts in litter with different moisture contents. Poultry Science 2001;80:1412-1415.

Waletzky E, Neal R, Hable I. A field strain of Eimeria tenella resistant to sulfonamides. Journal of Parasitology 1954;40(Suppl 2):24.
Wallach M. The importance of transmission-blocking immunity in the control of infections by apicomplexan parasites. International Journal for Parasitolog y 1997;27:1159-1167.

Weber FH, Evans NA. Immunization of broiler chicks by in ovo injection of Eimeria tenella sporozoites, sporocysts, or oocysts. Poultry Science 2003;82:1701-1707.

Weber FH, Genteman KC, LeMay MA, Lewis DO, Sr., Evans NA. mmunization of broiler chicks by in ovo injection of infective stages of Eimeria. Poultry Science 2004;83:392-399.

Williams RB. Safety of the attenuated anticoccidial vaccine "Paracox" in broiler chickens isolated from extraneous coccidial infection. Veterinary Research Communications 1994:18:189-219.

Williams RB. Epidemiological studies of coccidiosis in the domestic fowl (Gallus gallus). II. Physical condition and survival of Eimeria acervulina oocysts in poultry house liter. Applied Parasitology 1995;36:90-96.

Williams RB. Epidemiological aspects of the use of live anticoccidial vaccines for chickens. International Journal for Parasitology 1998;28:10891098.

Williams RB. Anticoccidial vaccines for broiler chickens:pathway for success. Avian Pathology 2002;31:317-353.

Williams RB, Catchpole J. A new protocol for a challenge test to assess the efficacy of live anticoccidial vaccines for chickens. Vaccine 2000;18:1178-1185

Yang YZ, Little B, Meshnick SR. Alkylation of proteins by artemisinin:effects of heme, $\mathrm{pH}$ and drug structure. Biochemical Pharmacology 1994:48:569-573

Yim D, Kang SS, Kim DW, Kim SH, Lillehoj HS, Min W. Protective effects of Aloe vera-based diets in Eimeria maxima-infected broiler chickens. Experimental Parasitology 2011;127:322-325.

Zahid N. Comparison of effects of Echinacea purpurea juices and Nigella sativa seeds on performance, some blood parameters, carcass and meat quality of broilers [dissertation]. Stuttgart: Faculty of Agricultural Sciences, Universität Hohenheim; 2009.

Zhai Z, Yi L, Wu L, Senchina DS, Wurtele ES, Murphy PA, et al. Enhancement of innate and adaptive immune functions by multiple Echinacea species. Journal of Medicinal Food 2007;10:423-434.

Ziomko I, Karamon J, Cencek T, Gornowicz E, Skoracki A, Ashash, U. Prevention of broiler chick coccidiosis using the inactivated subunit vaccine CoxAbic $^{\circledR}$. Bulletin of the Veterinary Institute in Pulawy 2005:49:299-302 
In the article entitled Litter A Review of Approaches Targeting the Replacement of Coccidiostat Application in Poultry Production published in the Revista Brasileira de Ciência Avícolas/Brazilian Journal of Poultry Science, v17 (4):405-407, in page 405 where it was written

iv Special Infectious Agents Unit - Biosafety Level 3, King Fahad Medical Research Center, King Abdulaziz University, Jeddah, Saudi Arabia.

\section{the correct form is}

Iv Special Infectious Agents Unit - Biosafety Level 3, King Fahd Medical Research Center, King Abdulaziz University, Jeddah, Saudi Arabia. 